\title{
Screening for retinopathy of prematurity: evaluation and modification of guidelines
}

\section{E Larsson, G Holmström}

See end of article for authors' affiliations

Correspondence to Gerd Holmström, MD, PhD, Department of Ophthalmology, University Hospital, S 75895

Uppsala, Sweden; gerd.holmstrom@ogon.uu.se

Accepted for publication 2 July 2002

\begin{abstract}
Aims: To evaluate current screening guidelines for ROP (retinopathy of prematurity) and to determine whether they can be modified.

Methods: In accordance with the authors' present criterion, infants born in Stockholm County, Sweden, from 1 August 1998 to 31 July 2000, with a gestational age of $\leqslant 32$ weeks, were screened for ROP. The effectiveness of screening was studied.

Results: The incidence of ROP was $25.5 \%$ in this study. A dropout group comprising almost $20 \%$ of the population studied ( $\leqslant 32$ weeks), was never referred, were lost to follow up, or died before screening was completed. No infant with a gestational age of $>31$ weeks at birth developed severe ROP (stages 3-5) and no infant with a gestational age of $>29$ weeks was treated for ROP.

Conclusion: $80 \%$ of infants in this population with a gestational age at birth of $\leqslant 32$ weeks, the current screening criterion, were effectively screened for ROP. The authors recommend that the screening criterion be lowered to $\leqslant 31$ weeks since no infant with severe ROP would have been missed.
\end{abstract}

$\mathrm{S}$ reening for ROP (retinopathy of prematurity) was started in many countries at the end of the 1980s, when the American Cryo ROP study reported its first positive results of cryotherapy. ${ }^{1}$ The main aim of screening is to detect infants needing treatment for ROP. Screening, however, is expensive, time consuming, and stressful for the infant, which emphasises the importance of adequate screening of infants with a minimum of resources.

National variations in neonatal and general health care, socioeconomic factors, criteria for treatment of ROP, etc, make it necessary to adapt screening programmes to each country and revise them regularly. Screening guidelines for ROP were introduced in our area a decade ago. They were based on an epidemiological study on the incidence of $\mathrm{ROP}^{2}$ and on other international studies. ${ }^{3-5}$ Since then, infants with a gestational age of 32 weeks or less at birth are regularly screened for ROP starting in the fifth postnatal week.

In a recent study on the incidence of ROP in two consecutive, epidemiological studies in the Stockholm area in Sweden, it was reported that "more mature" infants have a lower risk of ROP today than a decade ago. ${ }^{6}$ The aim of this study was to evaluate our screening guidelines ${ }^{2}$ and determine whether they can be modified.

\section{PATIENTS AND METHODS}

A prospective, population based study was performed in Stockholm County, Sweden, from 1 August 1998 to 31 July

Table 1 Incidence of ROP, mean gestational age at birth (weeks), and mean birth weight (g)

\begin{tabular}{lcll}
\hline & No (\%) & $\begin{array}{l}\text { Mean gestational } \\
\text { age (weeks) (range) }\end{array}$ & $\begin{array}{l}\text { Mean birth weight } \\
\text { (g) (range) }\end{array}$ \\
\hline No ROP & $292(74.5)$ & $30.3(25-32)$ & $1516(616-2705)$ \\
ROP 1 & $22(5.6)$ & $28.1(24-32)$ & $1136(734-1750)$ \\
ROP 2 & $30(7.7)$ & $27.7(24-32)$ & $1075(634-1885)$ \\
ROP 3 & $46(11.7)$ & $25.9(23-31)$ & $876(591-1640)$ \\
ROP 4 & $2(0.5)$ & $24.5(24-25)$ & $544(462-626)$ \\
ROP 5 & 0 & & \\
\hline
\end{tabular}

2000. Infants with a gestational age of 32 weeks or less at birth, our present screening criterion, ${ }^{2}$ who had survived for at least 8 weeks, were included in the study. The Swedish National Board of Health and Social Welfare provided us with data on the total number of liveborn infants in the area during the study and also on liveborn infants with a gestational age of less than 33 weeks.

All infants were examined regularly by experienced ophthalmologists at 1-2 week intervals from 5 postnatal weeks onwards. They were excluded if the examinations were stopped too early, before the retina was completely vascularised, or started too late-that is, after full vascularisation or more than 8 weeks after birth. The eyes were dilated with a combination of cyclopentolate $0.5 \%$ and phenylephrine $0.5 \%$ drops. Indirect ophthalmoscopy with a 20-30 dioptre lens was performed. If the border between vascularised and unvascularised retina could not be seen, we used a lid speculum and indentation. The criterion for treatment was stage 3 in at least 4 contiguous clock hours in zone II, even in the absence of "plus disease." Treatment with laser was performed within 72 hours of detecting this finding.

For some of the analyses, ROP was classified into mild ROP (stages 1 and 2) and severe ROP (stages 3-5).

\section{Statistical analysis}

We used the Wilcoxon matched pair signed ranks test to compare the eyes for the stage of ROP. Stepwise logistic regression analyses (combining the backward elimination and forward selection methods) were done to determine the most important risk factors for ROP. The predicted probability of ROP was calculated from the logistic regression model. The severity of ROP was also classified into three response categories-that is, no, mild, and severe. A logistic model was then performed and the predicted probability for each category of ROP was calculated.

\section{RESULTS}

From 1 August 1998 to 31 July 2000, 533 infants with a gestational age at birth of $\leqslant 32$ weeks were born in Stockholm County. They comprised $1.39 \%$ of all 38430 liveborn infants during the study. Forty six of the infants died during the first 


\begin{tabular}{|c|c|c|c|c|c|c|c|c|c|c|c|}
\hline & \multicolumn{10}{|c|}{ Gestational age at birth (weeks) } & \multirow[b]{2}{*}{ Total } \\
\hline & 23 & 24 & 25 & 26 & 27 & 28 & 29 & 30 & 31 & 32 & \\
\hline Total & 2 & 9 & 17 & 29 & 30 & 32 & 50 & 65 & 65 & 93 & 392 \\
\hline $\begin{array}{l}\text { No ROP } \\
(\%)\end{array}$ & $\begin{array}{l}0 \\
\text { (0) }\end{array}$ & $\begin{array}{l}0 \\
\text { (0) }\end{array}$ & $\begin{array}{l}2 \\
(11.8)\end{array}$ & $\begin{array}{l}4 \\
(13.8)\end{array}$ & $\begin{array}{l}14 \\
(46.7)\end{array}$ & $\begin{array}{l}21 \\
(65.6)\end{array}$ & $\begin{array}{l}43 \\
(86.0)\end{array}$ & $\begin{array}{l}58 \\
(89.2)\end{array}$ & $\begin{array}{l}62 \\
(95.4)\end{array}$ & $\begin{array}{l}88 \\
(94.6)\end{array}$ & 292 \\
\hline $\begin{array}{l}\text { Mild ROP } \\
(\%)\end{array}$ & $\begin{array}{l}0 \\
\text { (0) }\end{array}$ & $\begin{array}{l}2 \\
(22.2)\end{array}$ & $\begin{array}{l}2 \\
(11.8)\end{array}$ & $\begin{array}{l}12 \\
(41.4)\end{array}$ & $\begin{array}{l}10 \\
(33.3)\end{array}$ & $\begin{array}{l}8 \\
(25.0)\end{array}$ & $\begin{array}{l}5 \\
(10.0)\end{array}$ & $\begin{array}{l}6 \\
(9.2)\end{array}$ & $\begin{array}{l}2 \\
(3.0)\end{array}$ & $\begin{array}{l}5 \\
(5.4)\end{array}$ & 52 \\
\hline $\begin{array}{l}\text { Severe ROP } \\
\text { Not treated (\%) }\end{array}$ & $\begin{array}{l}0 \\
\text { (0) }\end{array}$ & $\begin{array}{l}0 \\
\text { (0) }\end{array}$ & $\begin{array}{l}4 \\
(23.5)\end{array}$ & $\begin{array}{l}5 \\
(17.2)\end{array}$ & $\begin{array}{l}4 \\
(13.3)\end{array}$ & $\begin{array}{l}0 \\
(0)\end{array}$ & $\begin{array}{l}1 \\
(2.0)\end{array}$ & $\begin{array}{l}1 \\
(1.6)\end{array}$ & $\begin{array}{l}1 \\
(1.6)\end{array}$ & $\begin{array}{l}0 \\
\text { (0) }\end{array}$ & 16 \\
\hline $\begin{array}{l}\text { Severe ROP } \\
\text { Treated (\%) }\end{array}$ & $\begin{array}{l}2 \\
(100)\end{array}$ & $\begin{array}{l}7 \\
(77.8)\end{array}$ & $\begin{array}{l}9 \\
(52.9)\end{array}$ & $\begin{array}{l}8 \\
(27.6)\end{array}$ & $\begin{array}{l}2 \\
(6.7)\end{array}$ & $\begin{array}{l}3 \\
(9.4)\end{array}$ & $\begin{array}{l}1 \\
(2.0)\end{array}$ & $\begin{array}{l}0 \\
\text { (0) }\end{array}$ & $\begin{array}{l}0 \\
(0)\end{array}$ & $\begin{array}{l}0 \\
\text { (0) }\end{array}$ & 32 \\
\hline $\begin{array}{l}\text { Total ROP } \\
(\%)\end{array}$ & $\begin{array}{l}2 \\
(100)\end{array}$ & $\begin{array}{l}9 \\
(100)\end{array}$ & $\begin{array}{l}15 \\
(88.2)\end{array}$ & $\begin{array}{l}25 \\
(86.2)\end{array}$ & $\begin{array}{l}16 \\
(53.3)\end{array}$ & $\begin{array}{l}11 \\
(34.4)\end{array}$ & $\begin{array}{l}7 \\
(14.0)\end{array}$ & $\begin{array}{l}7 \\
(10.8)\end{array}$ & $\begin{array}{l}3 \\
(4.6)\end{array}$ & $\begin{array}{l}5 \\
(5.4)\end{array}$ & \\
\hline
\end{tabular}

7 weeks of life, leaving a total study population of 487 infants with a survival rate of $91.4 \%$ at 8 weeks. Sixty two infants were never referred to us, 30 were excluded because fundus examinations were started too late (13) or stopped too early (17), and three infants died before screening was completed. This gave a dropout group of 95 (95/487, 19.5\%) infants and a study group of 392 infants.

There were $181(46.2 \%)$ girls and $211(53.8 \%)$ boys in the study group, and 295 (75.3\%) infants were products of singleton and $97(24.7 \%)$ of multiple deliveries. The mean gestational age at birth of the total group was 29.4 (range 23-32) weeks and the mean birth weight 1381 (range 462-2705) g.

The first examination was done at 5-6 weeks after birth in $376(96 \%)$ infants, and at 7-8 weeks after birth in $16(4 \%)$ infants. Infants examined later had been excluded (see methods).

ROP was found in $25.5 \%$ (100/392) of the infants in the study group. These infants had a mean gestational age of 26.9 (23-32) weeks at birth and a mean birth weight of 987 (4621885 ) g. Mild ROP (stages 1 and 2) was found in $13.3 \%$ $(52 / 392)$ and severe ROP (stages 3-5) in $12.2 \%$ (48/392). We found no significant difference between the eyes, with regard to the stage of ROP. The number of infants with each stage of ROP and their mean gestational ages and birth weights are shown in Table 1.
The dropout group included 95 infants of whom five had a gestational age of 26 weeks or less at birth, 15 an age of 27-29 weeks, and 75 an age of 30-32 weeks. Had the dropouts been included in the total study group, the incidence of ROP would have been $23.4 \%$ ( $11.9 \%$ mild, $11.5 \%$ severe ROP). In the dropout group, 62 infants were never referred to us by the neonatologists. Of these, 51 had a birth weight of more than $1500 \mathrm{~g}$.

The relation of ROP to gestational age at birth and birth weight is shown in Tables 2 and 3. Severe ROP developed in 48 of the 100 infants with ROP at a PMA (postmenstrual age) of 36.1 weeks (32-44 weeks). Of those with severe ROP, 67\% (32/ 48) progressed to "threshold disease" and underwent laser treatment, at a PMA of 37 weeks (32-45 weeks). Eleven infants were treated twice, five three times, and one infant a fourth time. Two of the laser treated infants were also operated on with cerclage in one of their eyes. The treated infants comprised $8.2 \%$ (32/392) of the total study population, and they had a mean gestational age of 25.4 (23-29) weeks at birth and a mean birth weight of $808(462-1640) \mathrm{g}$.

In a univariate logistic regression analysis, sex (girls higher risk, $\mathrm{p}=0.041$ ), single/multiple birth (single birth higher risk, $\mathrm{p}=0.01)$, gestational week at birth $(\mathrm{p}=0.0001)$, and birth weight ( $p=0.0001$ ) were identified as independent risk factors for ROP. In a multiple stepwise logistic regression analysis, gestational age at birth, birth weight, sex, and single/multiple birth were included as independent risk factors. Gestational

Table 3 Relation of ROP to birth weight

\begin{tabular}{|c|c|c|c|c|c|}
\hline & \multicolumn{4}{|c|}{ Birth weight (g) } & \multirow[b]{2}{*}{ Total } \\
\hline & $\leqslant 750$ & $751-1000$ & $1001-1500$ & $>1500$ & \\
\hline Total & 23 & 67 & 154 & 148 & 392 \\
\hline $\begin{array}{l}\text { No ROP } \\
(\%)\end{array}$ & $\begin{array}{l}2 \\
(8.7)\end{array}$ & $\begin{array}{l}23 \\
(34.3)\end{array}$ & $\begin{array}{l}127 \\
(82.5)\end{array}$ & $\begin{array}{l}140 \\
(94.6)\end{array}$ & 292 \\
\hline $\begin{array}{l}\text { Mild ROP } \\
(\%)\end{array}$ & $\begin{array}{l}4 \\
(17.4)\end{array}$ & $\begin{array}{l}22 \\
(32.9)\end{array}$ & $\begin{array}{l}20 \\
(13.0)\end{array}$ & $\begin{array}{l}6 \\
(4.0)\end{array}$ & 52 \\
\hline $\begin{array}{l}\text { Severe ROP } \\
\text { Not treated (\%) }\end{array}$ & $\frac{1}{(4.3)}$ & $\begin{array}{l}10 \\
(14.9)\end{array}$ & $\begin{array}{l}4 \\
(2.6)\end{array}$ & $\begin{array}{l}1 \\
(0.7)\end{array}$ & 16 \\
\hline $\begin{array}{l}\text { Severe ROP } \\
\text { Treated (\%) }\end{array}$ & $\begin{array}{l}16 \\
(69.6)\end{array}$ & $\begin{array}{l}12 \\
(17.9)\end{array}$ & $\begin{array}{l}3 \\
(1.9)\end{array}$ & $\begin{array}{l}1 \\
(0.7)\end{array}$ & 32 \\
\hline $\begin{array}{l}\text { Total ROP } \\
(\%)\end{array}$ & $\begin{array}{l}21 \\
(91.3)\end{array}$ & $\begin{array}{l}44 \\
(65.7)\end{array}$ & $\begin{array}{l}27 \\
(17.5)\end{array}$ & $\begin{array}{l}8 \\
(5.4)\end{array}$ & \\
\hline
\end{tabular}


Table 4 Stepwise logistic regression analysis of risk factors for ROP

\begin{tabular}{|c|c|c|c|c|}
\hline & $\begin{array}{l}\text { Log odds ratio } \\
\text { (b) }\end{array}$ & $\begin{array}{l}\text { Standard error } \\
\text { of } b\end{array}$ & Odds ratio & $95 \% \mathrm{Cl}$ of odds ratio \\
\hline Gestational age at birth & -0.6076 & 0.1144 & $1.836 *$ & 1.467 to 2.298 \\
\hline Birth weight & -0.00165 & 0.000689 & $1.179 \dagger$ & 1.030 to 1.349 \\
\hline
\end{tabular}

*Odds ratio for a reduction of 1 week in gestational age.

†Odds ratio for a reduction of $100 \mathrm{~g}$ in birth weight.

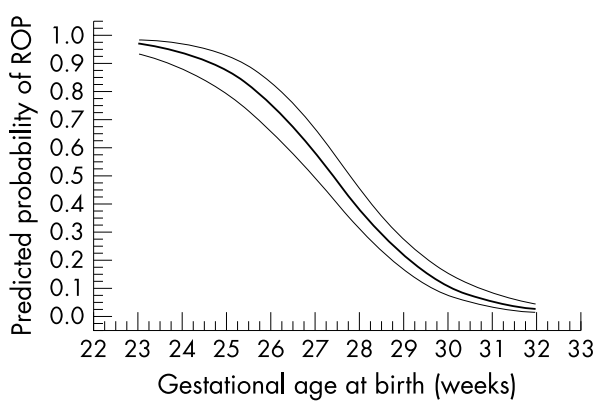

Figure 1 Predicted probability of ROP in relation to gestational age at birth and $95 \%$ confidence interval in the study group.

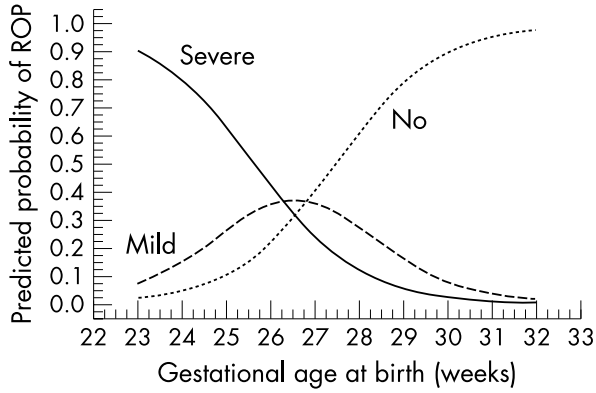

Figure 2 Predicted probability of no, mild, and severe ROP in relation to gestational age at birth in the study group.

age at birth was found to be the most important risk factor for ROP, followed by birth weight (Table 4). The decline in predicted probability for ROP with increasing gestational age is shown in Figure 1, and the predicted probability for mild and severe ROP, respectively, is shown in Figure 2. Detailed analysis of the probability of ROP in different weeks of gestational age at birth revealed a break point between weeks 30 and 31 with no further reduction in the probability of ROP after the 31st week of gestation.

At present, the recommended screening criterion for ROP in Sweden is a gestational age of $\leqslant 32$ weeks at birth. ${ }^{2}$ The effect of reducing the age of screening to $\leqslant 31, \leqslant 30, \leqslant 29$, and $\leqslant 28$ weeks - that is, the number of missed infants with ROP, is shown in Table 5.

\section{DISCUSSION}

In the present study, we detected ROP in $25.5 \%$ of the present study group of infants having a gestational age of 32 weeks or less at birth. This can be compared to ROP in $36.4 \%$ of infants having a birth weight of $1500 \mathrm{~g}$ or less in a recent population based study from the same period. ${ }^{6}$ Although our main aim was not to determine the incidence of ROP, the somewhat conflicting results show the need for clearly defined criteria in a given population and the difficulty of comparing findings in various studies.

Since we wished to evaluate the effectiveness of our screening guidelines for ROP, the dropout frequency of $19.5 \%$ $(95 / 487)$ was disappointing, because such screening has been well established in our area during the past decade. Thus, 62 infants were never referred to us by the neonatologists. One explanation may be uncertainty about when to refer infants, since in a previous epidemiological study of the incidence of $\mathrm{ROP}^{2}$ the criterion was $\leqslant 1500 \mathrm{~g}$, but in the present guidelines, a gestational age of $\leqslant 32$ weeks was recommended, introduced after that study. ${ }^{2}$ Fifty one of these 62 infants weighed more than $1500 \mathrm{~g}$, which supports this view.

Thirty infants were excluded because of inadequate frequency of examinations. Of these infants, the follow up was too short in 17, which illustrates a well known risk run by babies, who are transferred to another ward or hospital or discharged home. ${ }^{78}$ It also points out the need for continuous information about criteria for screening to neonatologists, staff in neonatal wards, and ophthalmologists.

"Threshold disease," according to our criteria for treatment, occurred in 32 of $48(66.7 \%)$ infants with severe ROP in the study group. For screening purposes, it is important to detect "threshold ROP" in time to advocate and perform treatment." We therefore believe that screening should aim to detect infants with severe ROP - that is, before such "threshold" is reached, an opinion supported by the findings of Gurdian et al on retinal detachment without previous plus disease in very immature infants. ${ }^{10}$ In the present study we achieved this goal. All treated infants had been examined at least once before the criteria for treatment were fulfilled-that is, all infants were diagnosed in time to treat them adequately.

The first examination was done at 5-6 weeks after birth in $96 \%$ of the infants. The timing of the first examination has been debated. Vascular events, including onset of ROP, have been shown to have a close correlation to the postmenstrual age (PMA) ${ }^{11-13}$ In the present study, ROP stage 3 was first

Table 5 Number of infants with various stages of ROP who would have been missed, if the present screening criterion of $\leqslant 32$ weeks of gestation at birth had been reduced to $\leqslant 31, \leqslant 30$, $\leqslant 29$, and $\leqslant 28$ weeks

\begin{tabular}{lllll}
\hline $\begin{array}{l}\text { Screening criteria } \\
\text { (weeks) }\end{array}$ & $\begin{array}{l}\text { No of infants } \\
\text { fulfilling criteria }\end{array}$ & $\begin{array}{l}\text { No of infants } \\
\text { missed with mild } \\
\text { ROP }\end{array}$ & $\begin{array}{l}\text { No of infants } \\
\text { missed with severe } \\
\text { ROP (not threshold) }\end{array}$ & $\begin{array}{l}\text { No of infants } \\
\text { "threshold" }\end{array}$ \\
\hline$\leqslant 32$ & 392 & 0 & 0 & 0 \\
$\leqslant 31$ & 299 & 5 & 0 & 0 \\
$\leqslant 30$ & 234 & 7 & 1 & 0 \\
$\leqslant 29$ & 169 & 13 & 2 & 0 \\
$\leqslant 28$ & 119 & 18 & 3 & 1 \\
\hline
\end{tabular}


detected at a PMA of 32 to 44 weeks (mean 36.1 weeks). In the most immature infants, however, ROP may develop earlier than expected. ${ }^{214-17}$ Accordingly, Subhani et al recently advocated that fundus examinations should start at a postnatal age of 5-6 weeks in these very immature infants, instead of using the PMA as a criterion for screening for ROP. ${ }^{17}$ This view has also been considered in the screening guidelines in the United Kingdom (first examination at 6-7 weeks) ${ }^{18}$ and the United States (first examination at 4-6 weeks postnatal age or between 31 and 33 weeks postconceptional age, whichever is sooner).${ }^{19}$ It also accords with our present recommendation of a first examination at 5 weeks of postnatal age.

In the present study and in the two consecutive population based studies on the incidence of ROP in our area, gestational age at birth was the most important risk factor for ROP in multiple regression analyses. ${ }^{6}$ Therefore, gestational age will remain the basis of screening in our population. Nearly all women in Sweden have their pregnancies dated by ultrasonography, which supports this view.

National screening programmes must consider the local circumstances in the country, such as neonatal and maternal care and the general healthcare system. ${ }^{20}{ }^{21}$ However, it is not wise to base such programmes on a single study with a limited number of infants. ${ }^{22}$ When considering a modification of our present screening programme, we have therefore also taken into account other national screening programmes, such as those of the British Royal College of Ophthalmologists $(<1500$ $\mathrm{g}$ and $\leqslant 3(\text { weeks })^{18}$ and the American Academies/Associations of Pediatrics, Pediatric Ophthalmology, Ophthalmology $\left(\leqslant 1500 \mathrm{~g}\right.$ or $\leqslant 28$ weeks). ${ }^{19}$ If the British or American guidelines had been applied to our study population, one infant with a gestational age of 29 weeks at birth and a birth weight of $1640 \mathrm{~g}$ would have been missed. In our population, gestational age at birth is the most important risk factor for ROP and, hence, seems to be suitable as a criterion for screening.

Screening for ROP in Sweden is recommended for all infants born at $\leqslant 32$ weeks of gestation. In the present study group (Table 1), no infant with severe ROP-that is, stage 3 or more, had a gestational age at birth of $>31$ weeks, and no infant treated for ROP had a gestational age at birth of $>29$ weeks. The analysis of predicted probability for ROP showed a breakpoint between weeks 30 and 31. If we had reduced the age of screening to $\leqslant 30$ weeks, we would have missed one infant with severe ROP (stage 3), but no infant who fulfilled our criterion for treatment (Table 5). If we had reduced the age of screening to $\leqslant 31$ weeks, five infants with mild ROP would have been missed, but no infant with severe ROP, which is the goal of our screening.

Modifications of the guidelines should be considered regularly, but require prospective consecutive studies of the incidence of ROP in the same populations and periodic review of the effectiveness of the guidelines. ${ }^{22}$ In Stockholm County, although the incidence of ROP has not changed during two consecutive periods one decade after the other, the distribution of ROP has-that is, the risk is lower in the most mature infants. ${ }^{6}$ The present evaluation of our guidelines for ROP shows that a reduction by 1 week to $\leqslant 31$ weeks would still enable us to detect ROP stage 3 , the aim of our screening. We therefore suggest that the screening limits in our population should be lowered to $\leqslant 31$ weeks. In the present study population this would have reduced the work load by 93 infantsthat is, about 50 infants a year.

\section{CONCLUSION}

An evaluation of our present screening guidelines for ROP shows that, although screening has been well established for many years, some infants are still missed, most of whom, however, are more "mature" infants with a low risk of ROP.
Continuous information about guidelines to neonatologists and ophthalmologists is needed to reduce the loss to follow up. On the basis of this evaluation of our screening programme, we suggest that the screening criteria for ROP in Sweden be modified by lowering the gestational age of the infants from $\leqslant 32$ to $\leqslant 31$ weeks at birth.

\section{ACKNOWLEDGEMENTS}

We thank Elisabeth Berg, Department of Humanities, Informatics and Social Sciences, Karolinska Institutet, Stockholm, for help with the statistical evaluation and Anna Norman, the Swedish National Board of Health and Social Welfare, for providing us with epidemiological data. We also thank Berit Carle-Petrelius, Gunilla Cernerud, Lena Ots, and Agneta Wallin for helping us with the fundus examinations. This study was supported by Sigvard and Marianne Bernadotte Research Foundation for Children's Eye Care.

\section{Authors' affiliations}

E Larsson, G Holmström, Department of Ophthalmology, University Hospital, Uppsala, Sweden

\section{REFERENCES}

1 Cryotherapy for Retinopathy of Prematurity Cooperative Group. Multicenter Trial of Cryotherapy for Retinopathy of Prematurity. Preliminary results. Arch Ophthalmol 1988;106:471-9.

2 Holmström G, el Azazi M, Jacobson L et al. A population-based, prospective study of the development of ROP in prematurely born children in the Stockholm area of Sweden. Br J Ophthalmol 1993; 77:417-23.

$3 \mathrm{Ng}$ YK, Fielder AR, Shaw DE, et al. Epidemiology of retinopathy of prematurity. Lancet 1988;ii:1235-8.

4 Darlow BA. Incidence of retinopathy of prematurity in New Zealand. Arch Dis Child 1988;63:1083-6.

5 Fledelius HC, Rosenberg T. Retinopathy of prematurity. Where to set screening limits? Recommendations based on two Danish surveys. Acto Paediatr Scand 1990;79:906-10.

6 Larsson E, Carle-Petrelius B, Cernerud G, et al. Incidence of ROP in two consecutive Swedish population-based studies. Br J Ophthalmol (in press).

7 Demorest BH. Retinopathy of prematurity requires diligent follow-up care. Surv Ophthalmol 1996;41:175-8

8 Haines L, Fielder AR, Scrivener R, et al on behalf of the Royal College of Paediatrics and Child Health, the Royal College of Ophthalmologists and British Association of Perinatal Medicine. Retinopathy of prematurity in the UK 1: the organisation of services for screening and treatment. Eye $2002 ; 16: 33-8$.

9 Good WV. Screening for retinopathy of prematurity: no ophthalmologist required? Br J Ophthalmol 2000;84:127-8.

10 Gurdian SJ, Gehlbach PL, Hunyor AP, et al. Retinal detachment associated with subthreshold retinopathy of prematurity. J Pediatr Ophthalmol Strabismus 2001;38:279-83

11 Fielder AR, Ng YK, Levene MI. Retinopathy of prematurity: age at onset. Arch Dis Child 1986:61:774-8.

12 Palmer EA, Flynn JT, Hardy RJ, et al. Incidence and early course of retinopathy of prematurity. Ophthalmology 1991;98:1628-40.

13 Repka MX, Palmer EA, Tung B. For the cryotherapy for retinopathy of prematurity cooperative group. Involution of retinopathy of prematurity. Arch Ophthalmol 2000;1 18:645-9.

14 Fielder AR, Shaw DE, Robinson J, et al. Natural history of retinopathy of prematurity: a prospective study. Eye 1992;6:233-42

15 Quinn GE, Johnson L, Abbasi S. Onset of retinopathy of prematurity as related to postnatal and postconceptional age. $\mathrm{Br} J$ Ophthalmol 1992:76:284-8

16 Coats DK, Paysse EA, Steinkuller PG. Threshold retinopathy of prematurity in neonates less than 25 weeks' estimated gestational age. $J$ AAPOS 2000;4:183-5

17 Subhani $M$, Combs A, Weber $P$, et al. Screening guidelines for retinopathy of prematurity: the need for revision in extremely low birth weight infants. Pediatrics 2001;107:656-9.

18 Royal College of Ophthalmologists British Association for Perinatal Medicine. Retinopathy of prematurity. Guidelines for screening and treatment. London: The Royal College of Ophthalmologists British Association for Perinatal Medicine, 1995

19 American Academy of Pediatrics, the American Association for Pediatric Ophthalmology and Strabismus, and the American Academy of Ophthalmology. Screening examinations of premature infants for retinopathy of prematurity. Ophthalmology 1997; 104:888-9.

20 Todd DA, Cassell C, Kennedy J, et al and the New South Wales neonatal intensive care units study group. Retinopathy of prematurity in infants < 32 weeks's gestation at birth in New South Wales in 1993 and 1994. J Paediatr Child Health 1999;35:355-7.

21 Fledelius H, Dahl H. Retinopathy of prematurity, a decrease in frequency and severity. Trends over 16 years in a Danish county. Acta Ophthalmol Scand 2000;78:359-61.

22 Goble RS, Jones HS, Fielder AR. Are we screening too many babies for retinopathy of prematurity? Eye 1997;11:509-14. 